\title{
Numerical Insights into the Formation and Stability of Cratons
}

\author{
CHARITRA JAIN ${ }^{1,2}$, ANTOINE ROZEL ${ }^{3}$, EMILY CHIN ${ }^{4}$ \\ AND JEROEN VAN HUNEN ${ }^{2}$ \\ ${ }^{1}$ GFZ German Research Centre for Geosciences, Geodynamic \\ Modelling Section \\ ${ }^{2}$ Department of Earth Sciences, Durham University \\ ${ }^{3}$ Institute of Geophysics, Department of Earth Sciences, ETH \\ Zurich \\ ${ }^{4}$ Scripps Institution of Oceanography, UC San Diego \\ Presenting Author: charitra.jain@gfz-potsdam.de
}

Geophysical, geochemical, and geological investigations have attributed the stable behaviour of Earth's continents to the presence of strong and viscous cratons underlying the continental crust. The cratons are underlain by thick and cold mantle roots, which are generally considered to be composed of melt-depleted and low density peridotite residues [1]. Progressive melt extraction increases the magnesium number $(\mathrm{Mg} \#)$ in the residual peridotite, thereby making the roots of cratons chemically buoyant [2] and counteracting their negative thermal buoyancy. Recent global models have shown the production of Archean continental crust (TTG rocks) by two-step mantle differentiation, however this primordial crust gets recycled and no stable continents form [3]. This points to the missing ingredient of cratonic lithosphere in these models, which could act as a stable basement for the crustal material to accumulate on and may also help with the transition of global regime from "vertical tectonics" to "horizontal tectonics". Based on the bulk $\mathrm{FeO}$ and $\mathrm{MgO}$ content of the residual peridotites, it has been proposed that cratonic mantle formed by hot shallow melting with mantle potential temperature, which was higher by 200-300 ${ }^{\circ} \mathrm{C}$ than present-day [4]. We introduce $\mathrm{Fe}-\mathrm{Mg}$ partitioning between mantle peridotite and melt to track the $\mathrm{Mg} \#$ variation through melting, and parametrise craton formation using the corresponding P-T formation conditions. Using self-consistent global convection models, we show the dynamic formation of cratons as a result of naturally occurring lateral compression and thickening of the lithosphere, which has been suggested by geochemical and petrological data. To allow for the material to compact and thicken, but prevent it from collapsing under its own weight, a combination of lithospheric strength, plastic yielding, dehydration strengthening, and depletion-induced density reduction of the depleted mantle material is necessary.

[1] Boyd, F. R. (1987), Mantle Xenolith, 403-412

[2] Jordan, T. H. (1979), The Mantle Sample: Inclusion in Kimberlites and Other Volcanics, 1-14.

[3] Jain, C., Rozel, A. B., Tackley, P. J., Sanan, P. \& Gerya, T. V. (2019) Gondwana Research 73, 96-122.

[4] Lee, C.-T. A. \& Chin, E. J. (2014), Earth and Planetary Science Letters 403, 273-286 